Journal for ImmunoTherapy of Cancer

\section{CD3xCD19 DART molecule treatment induces non-apoptotic killing and is efficient against high-risk chemotherapy and venetoclax-resistant chronic lymphocytic leukemia cells}

To cite: Martens AWJ, Janssen SR, Derks IAM, et al. CD3xCD19 DART molecule treatment induces non-apoptotic killing and is efficient against high-risk chemotherapy and venetoclax-resistant chronic lymphocytic leukemia cells. Journal for ImmunoTherapy of Cancer 2020;8:e000218. doi:10.1136/jitc-2019-000218

- Additional material is published online only. To view please visit the journal online (http://dx.doi.org/10.1136/jitc2019-000218).

GJWvdW and APK contributed equally.

Accepted 26 April 2020
Check for updates

(C) Author(s) (or their employer(s)) 2020. Re-use permitted under CC BY-NC. No commercial re-use. See rights and permissions. Published by BMJ.

For numbered affiliations see end of article.

Correspondence to Professor Arnon P Kater; a.p.kater@amsterdamumc.nl

\section{ABSTRACT}

Background Bispecific antibodies are promising new therapeutics in B cell malignancies. Whether they lead to potent $\mathrm{T}$ cell activation despite described $\mathrm{T}$ cell dysfunction in chronic lymphocytic leukemia (CLL), and are able to effectively target high-risk or venetoclax-resistant samples, is currently unknown.

Methods $\mathrm{CD} 19^{+}$cell lines or primary (high-risk) CLL were cocultured in vitro with healthy donor (HD) or CLLderived T cells in the presence of a CD3xCD19 dual affinity retargeting molecule (CD3xCD19 DART). Cell cytotoxicity, T cell activation, proliferation and effector molecule production were analyzed using flow cytometry. Results Here, we report that a bispecific CD3xCD19 DART mediates efficient killing by HD T cells of CD19+ cell-lines and primary CLL cells, regardless of immunoglobulin heavy chain variable region (IGHV) mutational status TP53 status or chemotherapy, ibrutinib or venetoclax sensitivity. Whereas TCR stimulation of CLL-derived T cells resulted in dysfunctional T cell activation and proliferation, treatment with CD3xCD19 DART led to a similar activation profile in CLL-derived and HD-derived T cells. Consistently, coculture of CLL derived T cells with JeKo-1 or CLL cells in the presence of CD3xCD19 DART resulted in significant cytotoxicity by both $\mathrm{CD} 4^{+}$and $\mathrm{CD} 8^{+} \mathrm{T}$ cells. On stimulation of CLL cells with CD40L, CLL cells become resistant to the specific inhibitor of anti-apoptotic $\mathrm{Bcl}-2$ protein venetoclax, due to upregulation of $\mathrm{Bcl}-2$ family members such as $\mathrm{Bcl}-\mathrm{XL}$. Nevertheless, CD40L stimulated CLL cells were as efficiently lysed on CD3xCD19 DART treatment as unstimulated CLL cells. Further examination of the mechanism of CD3xCD19 DART mediated killing showed that lysis was dependent on granules, but was independent of BAX/BAK or caspase activity, indicating non-apoptotic cell death.

Conclusions These data show that CD3xCD19 DART in CLL leads to robust $T$ cell activation and lysis of high-risk venetoclax resistant CLL cells through a non-apoptotic mechanism.

\section{BACKGROUND}

In recent years, treatment options for patients with chronic lymphocytic leukemia
(CLL) have greatly expanded through the introduction of targeted drugs such as the Bruton's tyrosine kinase inhibitor ibrutinib and Bcl-2 inhibitor venetoclax (ABT199). Although these new inhibitors induce durable responses and are generally well tolerated, they are not curative. ${ }^{1}$ In addition, patients need to remain on therapy continuously, leading to development of resistance, which has already been reported for both inhibitors. $^{23}$ Therefore, additional therapies for CLL are still urgently needed.

Allogeneic hematopoietic stem cell transplantations have shown as a proof-of-principle that long-lasting remissions can occur through a $\mathrm{T}$ cell-mediated graft-versus-leukemia effect. ${ }^{4-6}$ However, allogeneic stem cell transplantations cannot be widely applied in this elderly patient group due to high morbidity and mortality as a result of T-cell mediated graft-versus-host disease. ${ }^{4} 67$ Such adverse events could potentially be circumvented by applying autologous $\mathrm{T}$ cell therapies, such as chimeric antigen receptor (CAR) $\mathrm{T}$ cells and immune checkpoint blockade (ICB). CAR T cell therapy and ICB are effective in multiple B cell malignancies, ${ }^{8-10}$ but their efficacy in CLL remains disappointing. ${ }^{11-13}$ The limited responses of autologous based $\mathrm{T}$ cell therapies are likely due to the fact that $\mathrm{T}$ cells from CLL patients show a dysfunctional phenotype. CLL-derived T cells have a decreased proliferative and cytotoxic potential on stimulation, as well as impaired synapse formation. ${ }^{14} 15$ Furthermore, T cells of CLL patients have an exhausted phenotype and are skewed towards a short-lived effector phenotype. ${ }^{14}$ 16-18

A third class of autologous T cell therapy is represented by bispecific antibodies. Through 
binding to $\mathrm{CD} 3$, $\mathrm{T}$ cells are redirected, to a tumor cell by targeting of the other arm of the bispecific antibody to a tumor-associated antigen. Compared with the labor intensive and therefore expensive production of patient specific CAR T cells, bispecific antibodies have the advantage that they can be provided as off-the-shelf products. In contrast to CAR T cell therapy, this availability allows for repeated treatment. Therefore, bispecific antibodies are an attractive clinical option besides CAR T cells for CLL patients. Blinatumomab, a CD3xCD19 bispecific $\mathrm{T}$ cell engager (BiTE), has been the first bispecific to be approved by the Food and Drug Administration for treatment of patients with relapsed or refractory B cell precursor acute lymphoblastic leukemia. ${ }^{19}{ }^{20}$ Despite the well-known $\mathrm{T}$ cell dysfunction in CLL, blinatumomab has shown to be effective in vitro against CLL. ${ }^{21}$ Furthermore, CD3xCD19 bispecifics have been shown to induce immune synapse formation and have the potency to induce cell death in ibrutinib resistant CLL samples. ${ }^{22}$ However, because of a short half-life of the BiTE construct, patients need to be treated continuously. ${ }^{23}$ Bispecific dual affinity re-targeting (DART) molecules have increased stability due to both disulphide bonds that link the polypeptide chains and by tethering of the DART to an Fc domain, which could prolong half-life up to 6.7 days. ${ }^{24}$ Earlier it has been reported that CD3xCD19 DARTs led to T cell activation and tumor depletion of $\mathrm{B}$ cell malignancies in vitro. ${ }^{25}$

Because of the ability of bispecific antibodies to induce synapses in CLL, ${ }^{22}$ and based on the assumption that $\mathrm{T}$ cell-mediated cell death differs from venetoclax mediated lysis (which is dependent on the intrinsic apoptosis pathway), we hypothesized that CD3xCD19 DART treatment overcomes $\mathrm{T}$ cell dysfunction and will be effective against high-risk venetoclax-resistant samples.

Here, we demonstrate that $\mathrm{CD} 19^{+}$cell lines as well as high-risk primary CLL cells are efficiently killed by HD-derived and CLL-derived T cells in presence of the CD3xCD19 DART. CD3xCD19 DART treatment resulted in significant killing of both allogeneic and autologous CLL, mediated by both $\mathrm{CD} 4^{+}$and $\mathrm{CD}^{+}$cells. Furthermore, upregulation of anti-apoptotic molecules, leading to venetoclax resistance, did not affect CD3xCD19 DART mediated lysis, suggesting that non-apoptotic mechanisms are involved. Together, our data indicate that CD3xCD19 DART could serve as a potential salvation therapy in highrisk or venetoclax resistant CLL.

\section{MATERIALS AND METHODS Patients and controls}

Written informed consent was obtained from all subjects in accordance with the Declaration of Helsinki. Peripheral blood mononuclear cells (PBMCs) were isolated from peripheral blood of CLL patients (table 1) or buffy coats of (age-matched) HDs (table 2) from Sanquin Blood Supply (Amsterdam, The Netherlands) using Ficoll-Plaque (VWR). All samples were cryopreserved in liquid nitrogen and CLL samples used had a purity of
$\mathrm{CD}^{+} \mathrm{CD} 19^{+}$of at least $85 \%$. CLL patients were selected on their diagnosis $\left(\mathrm{CD}^{+} \mathrm{CD} 19^{+} \mathrm{CD} 23^{+}\right.$lymphocytosis), treatment history or chemoresistance.

\section{DART molecules}

The CD3xCD19 DART (JNJ-64052781, also known as MGD011) molecule was constructed as described. ${ }^{24}$ The CD3xCD19 DART is composed of anti-CD3 sequence XR32 and anti-CD19 sequence BU12. The control DART molecule, CD3xFITC, in which the variable domain sequences of the antifluorescein mAb 4-4-20 replaces the CD19 arm, was engineered in a similar manner. DART molecules were expressed transiently in CHO-S cells and purified to homogeneity by using protein $\mathrm{A}$.

\section{Culture conditions}

CLL cells, 3T3 and 3T40 (expressing CD40L) fibroblasts and Ramos cells were cultured in Iscove's Modified Dulbecco's Medium (Thermo Fisher Scientific). JeKo-1 and Daudi cells were cultured in RPMI 1640 medium (Thermo Fisher Scientific). Medium was supplemented with $10 \%$ fetal calf serum and $1 \%$ penicillin/streptomycin.

\section{Flow cytometry}

PBMCs were washed with PBA (phosphate buffered saline, $0.5 \%$ BSA and $0.02 \%$ sodium azide) and stained using fluorescently labeled antibodies for $20 \mathrm{~min}$ on ice. The following antibodies were used: CD3 Alexa Fluor (AF) 700 (eBioscience), CD3 allophycocyanin (APC) (eBioscience), CD3 V500 (BD Biosciences), CD4 Phycoerythrin (PE)-Cy7 (BD Biosciences), CD4 AF594 (Biolegend), CD4 Brilliant Violet (BV) 605 (BD Biosciences), CD5 PE (eBioscience), CD8 PerCPCy5.5 (BD Biosciences), CD8 V450 (BD Biosciences), CD8 PE-Cy7 (eBioscience), CD19 APC (BD Biosciences), CD20 FITC (BD Biosciences), CD25 APC (BD Biosciences), CD25 BV786 (BD Biosciences), CD71 FITC (eBioscience), CD107a PE-Cy7 (BD Biosciences), interferon $\gamma$ (IFN $\gamma$ ) Brilliant Ultraviolet (BUV) 395 (BD Biosciences), tumor necrosis factor- $\alpha$ (TNF $\alpha$ ) AF700 (BD Biosciences), Granzyme B AF647 (BD Biosciences), Perforin AF488 (Sony) and cleaved poly ADP-ribose polymerase (PARP) PE (BD Biosciences). To exclude dead cells, Fixable Viability Dye eFluor 780 or Fixable Viability Dye eFluor 506 (Thermo Fisher Scientific) was used according to manufacturer's instructions. For staining of intracellular cytokines or cleaved PARP, cells were fixed and permeabilized using the Fixation/ Permeabilization Solution Kit (BD Biosciences). After antibody staining, samples were washed using PBA and acquired on BD FACS Canto or LSR Fortessa flow cytometer and analyzed with FlowJo v10.

\section{$3 \mathrm{~T} 3$ and $3 \mathrm{~T} 40$ stimulation}

3T3 control or 3T40 fibroblasts were irradiated and plated as described. ${ }^{26}$ After 2 hours of adherence, CLL cells were added to the 3T3 or 3T40 fibroblasts. After 24-48 hours, CLL cells were removed from the fibroblasts and used as target cells in a cytotoxicity assay (see below). Effective CD40L stimulation of the CLL cells was confirmed by 


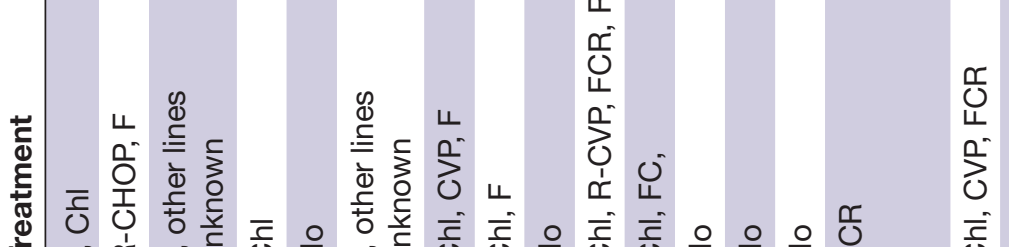

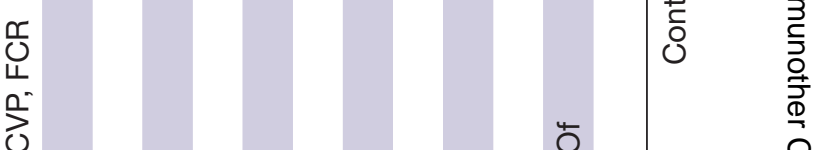
닌

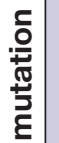

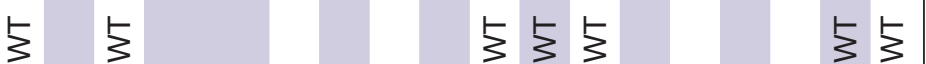

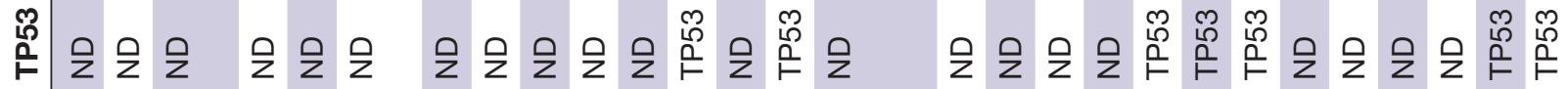

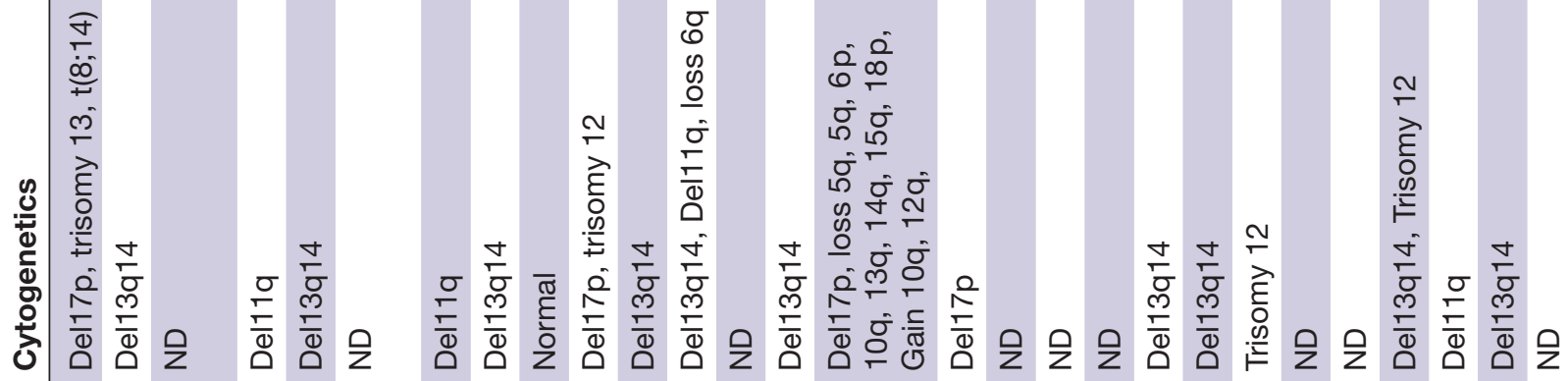

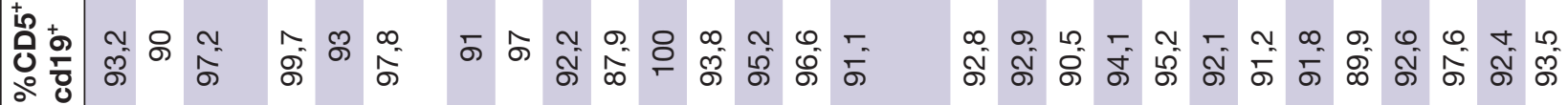
$\frac{0}{\frac{0}{x}}$

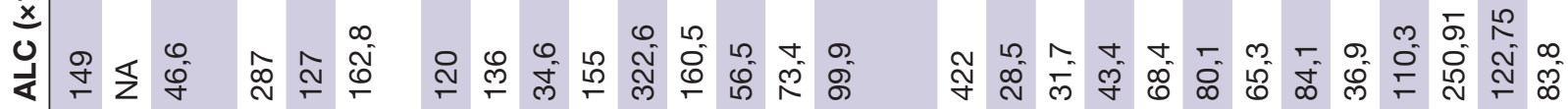

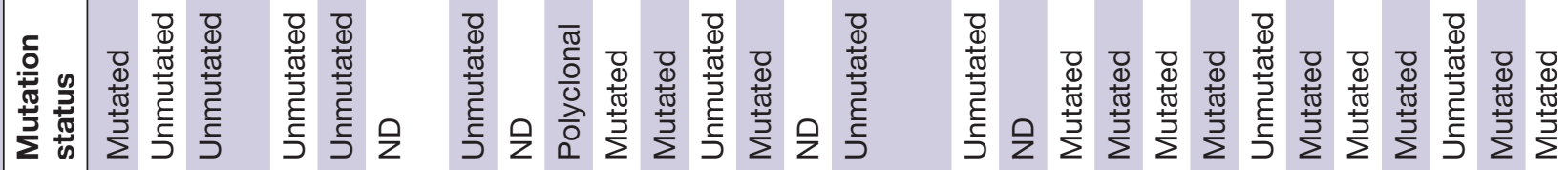

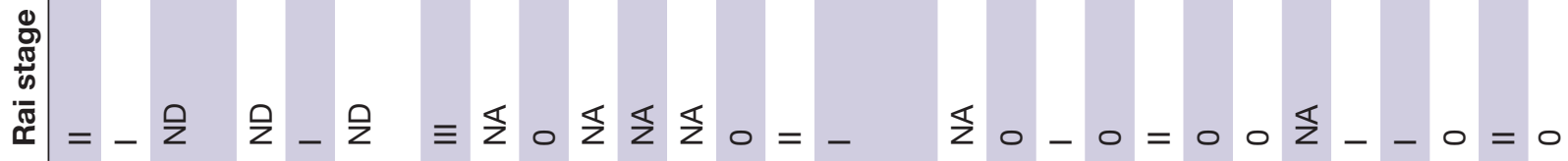
造

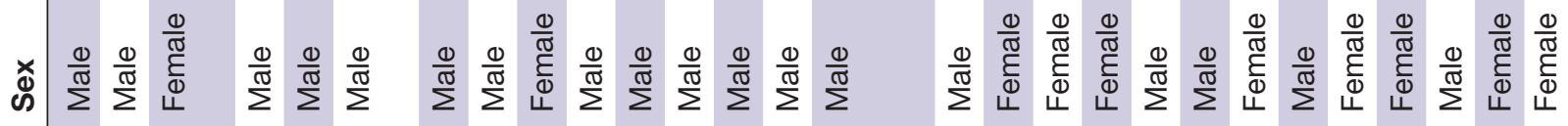

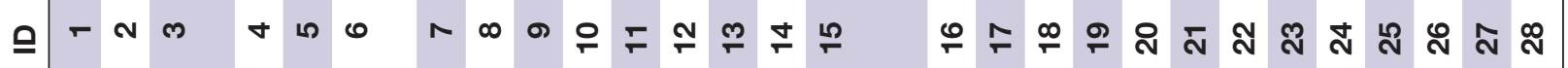


营

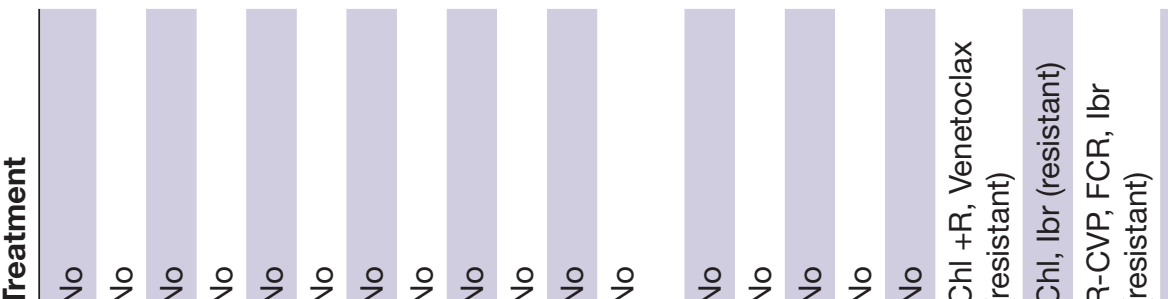

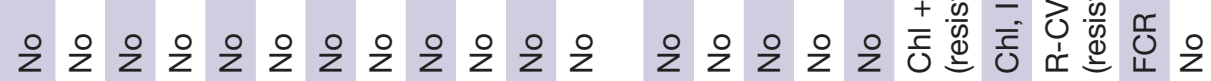

突

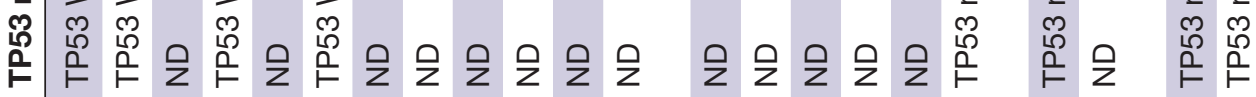

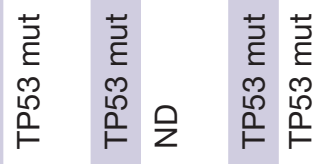

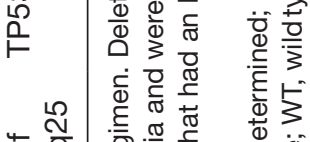

ড 을

음

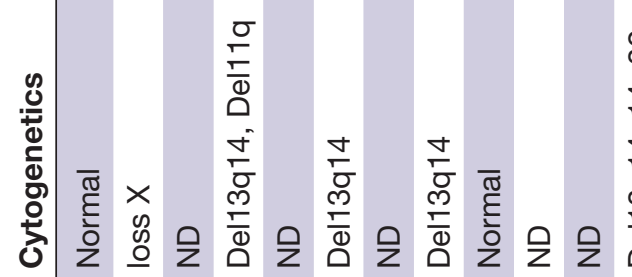

仓ें

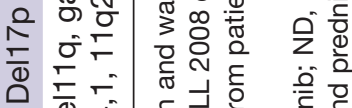

वे

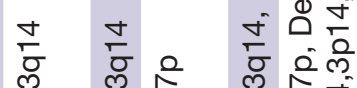

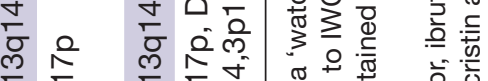

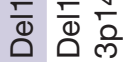

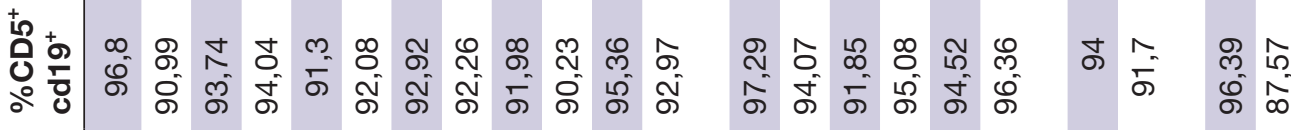

$\underset{\frac{0}{x}}{\frac{0}{x}}$

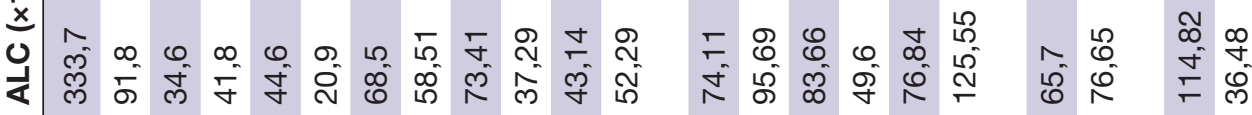

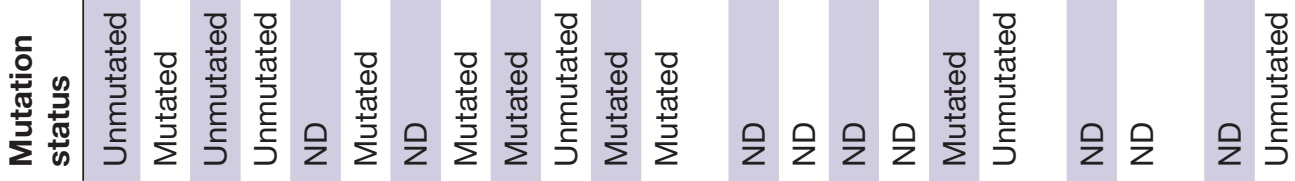

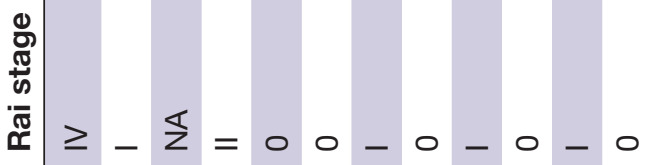

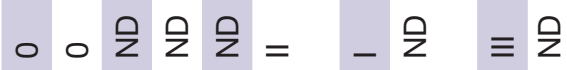

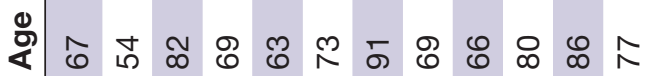

ㅇำ

$\infty \overline{0}$

$\notin$

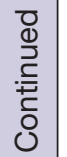

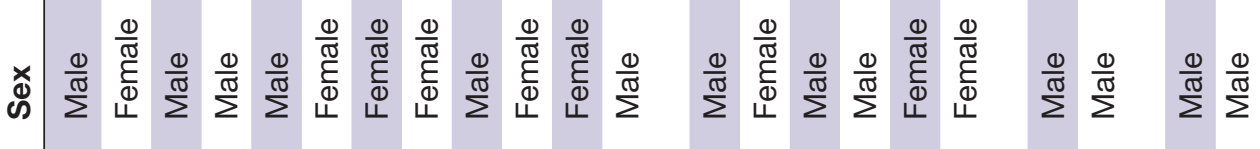

$\frac{\overline{0}}{\frac{0}{\circ}}$

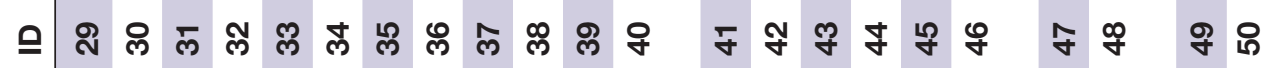

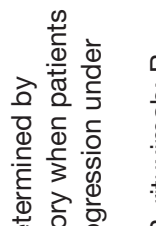

要产要

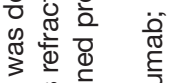

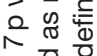

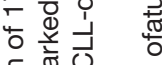

ธ을

ब

등.$\frac{\pi}{2} \stackrel{0}{5}$

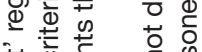

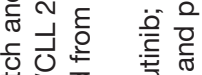

\% $\frac{1}{\pi}$ 产

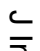

3

홍

बำ

$\overrightarrow{\overrightarrow{\vec{P}}}$

흠

$\frac{\mathrm{N}}{\overrightarrow{\mathrm{D}}}$

ळ

$\overrightarrow{0}$

$\vec{\omega}$

言

옹

\&

기

운

N

气

กิ

망

$\sum_{3}^{\circ}$

$\frac{\bigotimes}{\mathbb{D}}$

$\stackrel{2}{3}$

궁

㐔

훙.

ㅇํㄹ

의

O

仓市 离

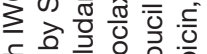

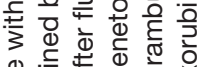

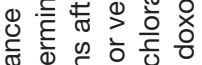

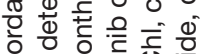

造造

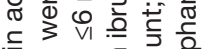

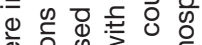

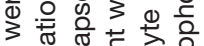

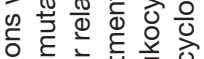

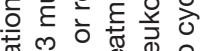
. क्ष

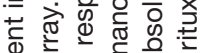

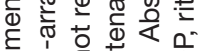

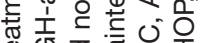




\begin{tabular}{|c|c|c|}
\hline ID & Sex & Age \\
\hline 1 & Male & 68 \\
\hline 2 & Male & 64 \\
\hline 3 & Female & 66 \\
\hline 4 & $?$ & 64 \\
\hline 5 & Female & 68 \\
\hline 6 & Female & 63 \\
\hline 7 & Female & 63 \\
\hline 8 & Male & 62 \\
\hline 9 & Male & 65 \\
\hline 10 & Male & 64 \\
\hline 11 & Male & 60 \\
\hline 12 & Female & 67 \\
\hline 13 & Male & 66 \\
\hline 14 & Male & 60 \\
\hline 15 & Male & 72 \\
\hline 16 & $?$ & $?$ \\
\hline 17 & $?$ & $?$ \\
\hline 18 & $?$ & $?$ \\
\hline 19 & Male & 60 \\
\hline
\end{tabular}

testing resistance of the 3T3 and 3T40 stimulated CLL cells to $10 \mathrm{nM}$ ABT-199 for 24 hours.

\section{Cytotoxicity assay}

Cell-lines or primary CLL samples were labeled with cell trace violet (CTV) (Thermo Fisher Scientific) according to manufacturer's instructions and cocultured with HD PBMCs or CLL derived (autologous) T cells in different effector to target (E:T) ratios. Where indicated, T cells were pretreated for 2 hours with $1 \mu \mathrm{M}$ concanamycin A (CMA) or dimethyl sulfoxide (DMSO) as a control. The treated $\mathrm{T}$ cells were thoroughly washed before using in the coculture. 10 or $20 \mu \mathrm{M}$ of the pan-caspase inhibitor QVD-OPh (APExBIO) was added to the cocultures where indicated. Viability of the target cells was assessed using TO-PRO-3 (Invitrogen) and MitoTracker Orange (Invitrogen) using Flow Cytometry. Specific lysis of target cells was calculated as (\% target cell death in treated sample - \% cell death target cells in medium control $) /(100-$ $\%$ cell death target cells in medium control) $* 100 \%$. Samples were excluded when cell death in medium controls exceeded $50 \%$.

\section{T cell proliferation and activation}

PBMCs from HD or CLL patients were labeled with CTV. PBMCs were incubated in the presence of $100 \mathrm{ng} / \mathrm{mL}$ CD3xCD19 DART or stimulated with CD3 (clone 1XE) and CD28 (clone 15E8) antibodies. After 2 days activation was measured and after 4 days proliferation and activation were measured by flow cytometry as described above.

\section{Cytokine production and degranulation}

PBMCs from HD or CLL patients were incubated in the presence of $100 \mathrm{ng} / \mathrm{mL}$ CD3xCD19 DART or stimulated with CD3 (clone 1XE) and CD28 (clone 15E8) antibodies for 2 days. Brefeldin A (10 ug/mL, Invitrogen), GolgiStop (BD Biosciences) and anti-CD107a PE-Cy7 were added 4-6 hours before assessment of degranulation and cytokine production by flow cytometry as described above.

\section{BAX/BAK knockout JeKo-1}

Bcl-2-associated X (BAX) and Bcl-2 homologous antagonist/killer (BAK) knockout (KO) JeKo-1 cells were generated using CRSIPR/Cas9 technology. Details regarding single guide RNAs (sgRNAs) targeting BAK and BAX have been published before. ${ }^{27}$ Each sgRNA was cloned in the lentiCRISPRv2 puro plasmid, a gift from Brett Stringer (Addgene \#98290). Lentivirus was produced and used to infect the cell-lines. After selection with puromycin (Sigma) and single cell cloning, knockouts were confirmed by SDS-PAGE with BAK and BAX antibodies (Cell Signaling).

\section{Statistical analysis}

To test for normal distribution a D'Agostino-Pearson test or a Shapiro-Wilk test if $n=4$, was used. $P$ values were calculated by using two-sided paired or unpaired t tests, Wilcoxon test, Mann-Whitney U test, one-way analysis of variance (followed by Tukey's post hoc test) or Friedman test (followed by Dunn's post hoc test). Statistical analysis was performed using Graphpad PRISM V.8.0.2 with significance set at $\mathrm{P}<0.05$.

\section{RESULTS \\ CD3XCD19 dart mediates HD T cell activation and lysis of $\mathrm{CD}^{+}{ }^{+}$cell-lines in vitro}

CD3xCD19 DART (JNJ-64052781 or MGD011) is an Fc bearing bispecific molecule with an approximate molecular weight of $109 \mathrm{kDa}$ and is composed of an anti CD3 (clone XR32) and anti CD19 domain (BU12). ${ }^{24}$ Previously it has been shown that this DART is specific for CD19, since CD19- cell lines are not affected. ${ }^{25}$ To assess whether this DART molecule treatment leads to robust $\mathrm{T}$ cell activation, age-matched HD PBMCs were cultured in presence of $100 \mathrm{ng} / \mathrm{mL}$ CD3xCD19 DART, and activation was compared with direct TCR stimulation with anti-CD3/CD28 antibodies. Robust T cell proliferation was observed when treating HD PBMCs with the CD3xCD19 DART for 4 days, equal to stimulation with anti-CD3/CD28 antibodies for $\mathrm{CD} 4^{+} \mathrm{T}$ cells (figure $1 \mathrm{~A}$ ). $\mathrm{CD}^{+} \mathrm{T}$ cells showed increased proliferation after treatment with CD3xCD19 DART (figure 1A). Furthermore, exposure to CD3xCD19 DART led to T cell activation as indicated by upregulation of activation markers CD25 and CD71, the degranulation marker CD107a, production of IFN- $\gamma$, TNF- $\alpha$, perforin, and granzyme $\mathrm{B}$ in both $\mathrm{CD} 4^{+}$and $\mathrm{CD} 8^{+} \mathrm{T}$ cells (figure $1 \mathrm{~B}-\mathrm{G}$ 
A

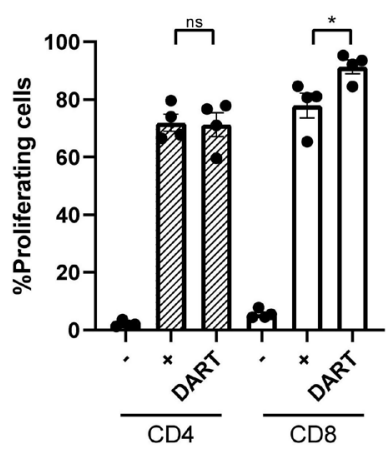

E
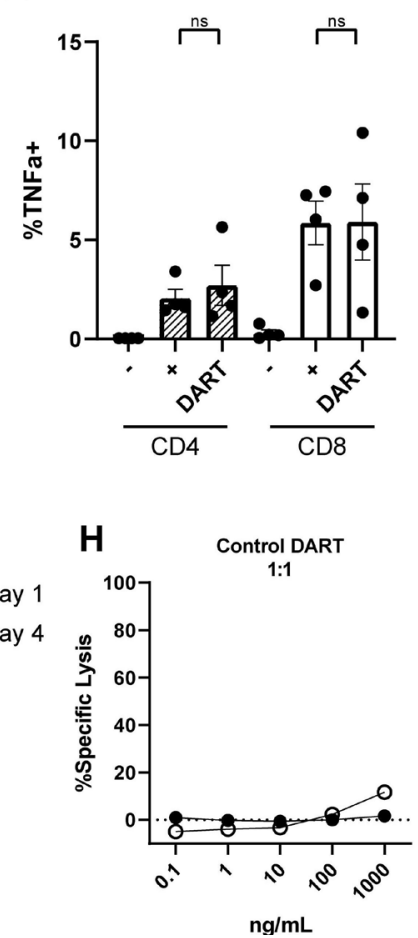

B

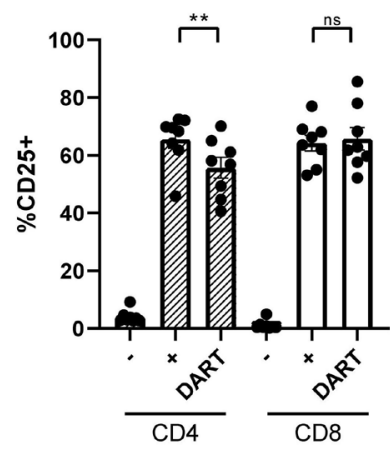

$\mathbf{F}$
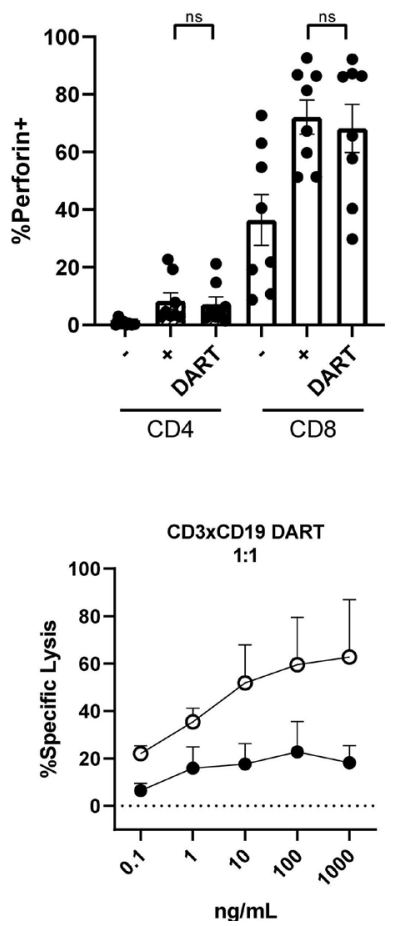

C
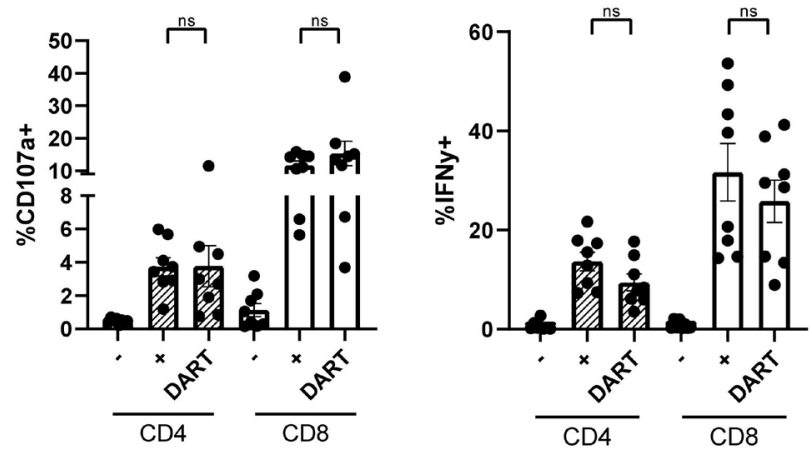

G

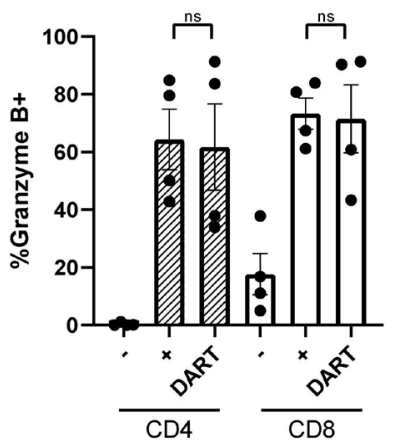

- = unstimulated

$+=$ anti-CD3/CD28

DART = CD3XCD19 DART

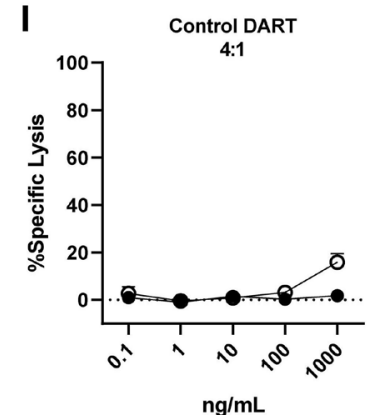

Figure 1 HD T cells become activated on CD3xCD19 dart treatment and are able to kill CD19+ cell-lines. (A-G) HD PBMCs were CTV labeled and left unstimulated or cultured in the presence of $100 \mathrm{ng} / \mathrm{mL}$ CD3xCD19 DART or anti-CD3/aCD28 antibodies. T cell proliferation (A) was measured after 4 days $(n=4)$. $(B-G)$ after 2 days induction of CD25 (B), degranulation measured by CD107a (C), IFN $\gamma$ production (D), TNF $\alpha$ production (E), perforin production (F) and granzyme B production (G) were measured by fluorescence-activated cell sorting (FACS) $(n=4-8)$. $(\mathrm{H}-\mathrm{l})$ FACS analysis of lysis of CTV labeled JeKo-1 cells cocultured in 1:1 $(\mathrm{H})$ or 4:1 (I) E:T ratios and with different concentrations of the CD3xFITC and CD3xCD19 DART molecules for 24 hours and 4 days $(n=2)$. ${ }^{*} P<0.05 ;{ }^{* *} P<0.01$. CTV, cell trace violet; DART, dual affinity retargeting; HD, healthy donor; IFN $\gamma$, interferon $\gamma$, ns, not significant; PBMCs, peripheral blood mononuclear cells; TNF $\alpha$, tumor necrosis factor- $\alpha$.

and online supplementary file S1A). Enhanced expression of CD25 and the effector molecules was similar in the CD3xCD19 DART conditions compared with anti-CD3/CD28 stimulation (figure 1B-G). As a proofof-principle that CD3xCD19 DART induces $\mathrm{T}$ cellmediated killing of $\mathrm{CD} 19^{+}$targets, we cocultured HD $\mathrm{T}$ cells with the $\mathrm{CD} 19^{+}$mantle cell lymphoma cell-line JeKo-1, in the presence of increasing concentrations of the functional CD3xCD19 DART or a control DART molecule (CD3xFITC). JeKo-1 was chosen because of its coexpression of CD5 and CD19 and loss of TP53, also a feature of high-risk CLL. ${ }^{28}$ Exposure of JeKo-1 cells to HD $\mathrm{T}$ cells in a 1:1 effector to target ratio in the presence of CD3xCD19 DART caused lysis of target cells already after 24 hours, which was further augmented when increasing CD3xCD19 DART concentrations, prolonging exposure up to 4 days (figure $1 \mathrm{H}$ ), or increasing E:T ratios (figure 1I). Exposure to the control DART molecule did not result in lysis of the CD19 ${ }^{+}$targets (figure 1H-I). CD3xCD19 DART mediated lysis of CD19-positive cell-lines was also observed using the Burkitt lymphoma cell-line Daudi, and was confirmed using $\mathrm{T}$ cells derived from different donors (online supplementary figure S1B,C). 


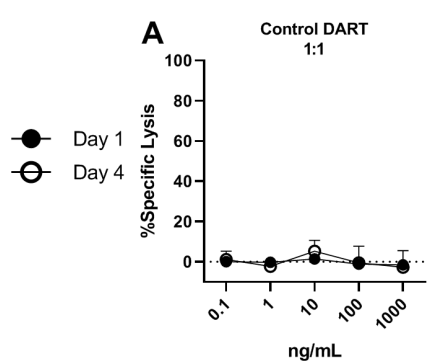

$\mathrm{ng} / \mathrm{mL}$

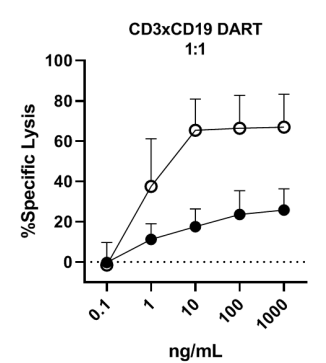

B

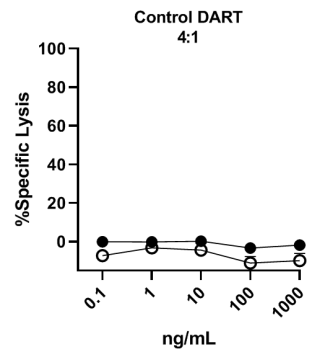

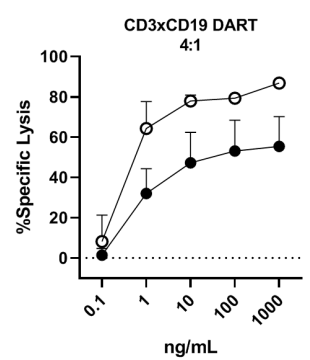

C

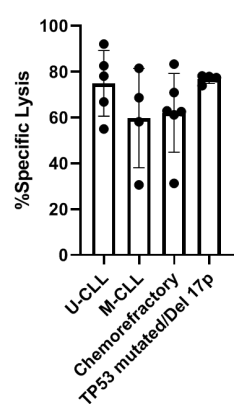

Figure 2 CD3xCD19 DART mediates lysis of primary CLL cells independent of IGHV mutation status, presence of TP53 aberrations or sensitivity to chemotherapy. (A-C) FACS analysis of lysis of CTV labeled primary CLL cocultured with healthy donor T cells in presence of CD3xCD19 DART. (A-B) Primary CLL cells cocultured in 1:1 (A) or 4:1 (B) E:T ratios and with different concentrations of the CD3xFITC and CD3xCD19 DART molecules for 24 hours and 4 days $(n=3)(C)$ lysis of unmutated IGHV $(n=5)$, mutated IGHV $(n=4)$, chemorefractory $(n=6)$ and TP53 mutated/17 $p$ deleted $(n=4)$ CLL by HD T cells in 4:1 E:T ratio after 4 days. CLL, chronic lymphocytic leukemia; CTV, cell trace violet; DART, dual affinity retargeting; HD, healthy donor; MCLL, mutated IGHV; U-CLL, mutated IGHV.

\section{CD3xCD19 DART mediates lysis of primary CLL cells independent of IGHV mutation status, presence of TP53 aberrations or chemotherapy or ibrutinib refractoriness}

To determine whether exposure to CD3xCD19 DART also leads to lysis of primary CLL cells, HD T cells were incubated with increasing concentrations of the CD3xCD19 DART or control DART molecule in the presence of primary CLL cells for 24 hours or 4 days. Killing of the primary CLL cells could already be observed after 24 hours in a 1:1 E:T ratio, and was dependent on the concentration of CD3xCD19 DART, the E:T ratio, and duration of exposure (4 days) (figure 2A-B and online supplementary S1D-G). Since the prognosis of CLL patients is dependent on the immunoglobulin heavy chain variable region (IGHV) mutational status, presence of TP53 aberrations and/or whether patients are relapsed or refractory after chemotherapy, we tested whether CD3xCD19 DART could induce lysis in unmutated IGHV, mutated IGHV CLL, cells derived from chemorefractory patients and TP53 mutated and/or $17 \mathrm{p}$ deleted patients. Lysis on $\mathrm{CD} 3 \mathrm{xCD} 19$ treatment was observed in all subgroups of patients (figure 2C and online supplementary figure $\mathrm{S} 1 \mathrm{H})$. Although, low numbers, first evidence is available that patients who become refractory on new agents such as ibrutinib are still sensitive to CD3xCD19 mediated lysis (online supplementary figure S1I). Taken together, using HD T cells, primary CLL cells can be efficiently lysed by using CD3xCD19 DART irrespective of IGHV mutation status, TP53 aberrations or sensitivity to chemotherapy.

\section{CD3xCD19 DART induces proliferation, activation and production of effector molecules in CLL-derived T cells}

$\mathrm{T}$ cells from CLL patients are known to be dysfunctional with regard to activation and proliferation. ${ }^{1415} 18$ To test whether CD3xCD19 DART exposure could overcome this dysfunctional phenotype, CLL PBMCs were cultured in the presence of $100 \mathrm{ng} / \mathrm{mL}$ CD3xCD19 DART or antiCD3/CD28 antibodies. As we and others have previously reported, ${ }^{18} 18$ TCR stimulation of CLL-derived T cells results in impaired proliferation and activation (as measured by upregulation of CD25 and CD71) compared with age-matched HD $\mathrm{T}$ cells (figure 3A,B, online supplementary figure S1J). Remarkably, addition of the CD3xCD19 DART induced robust proliferation in both $\mathrm{CD}^{+}$and $\mathrm{CD} 8^{+} \mathrm{T}$ cells derived from CLL patients (figure 3A), similar to HD T cells. In line with this, exposure to CD3xCD19 DART led to activation of $\mathrm{CD}^{+}$and $\mathrm{CD} 8^{+}$CLL derived $\mathrm{T}$ cells as indicated by upregulation of activation markers CD25 and CD71, the degranulation marker CD107a, production of IFN- $\gamma$, TNF- $\alpha$, perforin and granzyme B (figure 3B-G and online supplementary $\mathrm{S} 1 \mathrm{~J})$. Whereas impaired $\mathrm{T}$ cell activation was measured on TCR stimulation with anti-CD3/CD28 antibodies compared with healthy controls, CD3xCD19 DART treatment led to equal or even improved activation of CLL derived $\mathrm{T}$ cells (figure $3 \mathrm{~B}$, online supplementary figure S1J). Also, production of IFN- $\gamma$, TNF- $\alpha$ and perforin on CD3xCD19 DART treatment in HD and CLL-derived $\mathrm{T}$ cells was equal (figure 3D-G), yet degranulation was significantly increased in both $\mathrm{CD} 4^{+}$and $\mathrm{CD} 8^{+} \mathrm{T}$ cells in CD3xCD19 treated CLL derived T cells compared with HD (figure 3C). Interestingly, whereas both CLL and HD $\mathrm{CD}^{+} \mathrm{T}$ cells produce granzyme $\mathrm{B}$ on TCR or $\mathrm{CD} 3 \mathrm{xCD} 19$ DART, CLL derived $\mathrm{CD} 4^{+} \mathrm{T}$ cells lack behind compared with $\mathrm{HD}$ derived $\mathrm{CD} 4^{+} \mathrm{T}$ cells (figure $3 \mathrm{G}$ ). Nevertheless, granzyme $\mathrm{B}$ expression increased significantly in CLL derived $\mathrm{CD}^{+} \mathrm{T}$ cells on CD3xCD19 DART treatment compared to anti-CD3/CD28 stimulation (figure 3G). Taken together, while TCR stimulation with anti-CD3/ CD28 antibodies results in poor $\mathrm{T}$ cell activation, proliferation and degranulation in T cells of CLL patients, treatment with CD3xCD19 DART induces fully functional $\mathrm{T}$ cell responses in CLL samples.

\section{CD3xCD19 DART treatment mediates lysis of primary CLL cells by CLL-derived T cells}

Since it was determined that CD3xCD19 DART exposure leads to enhanced $\mathrm{T}$ cell activation, proliferation and production of effector molecules compared with TCR stimulation, we assessed whether T cells of CLL patients 


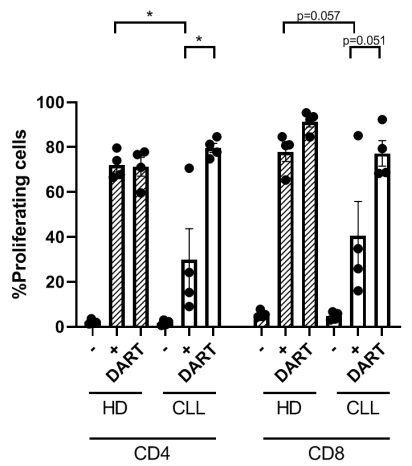

E

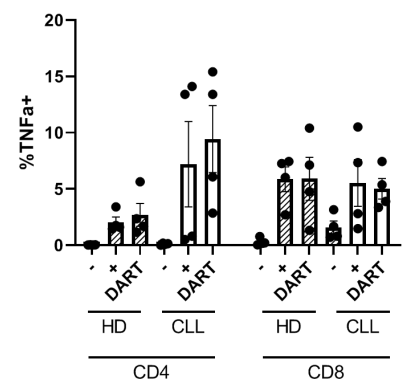

B

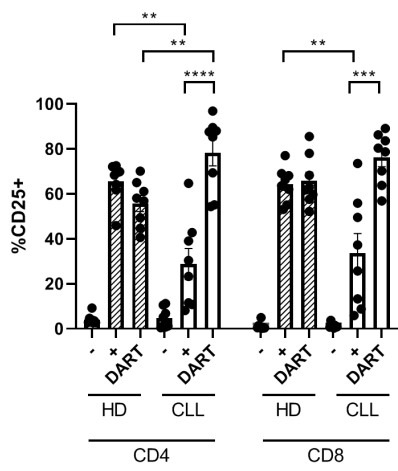

$\mathbf{F}$

$$
\dot{n} \quad \stackrel{* * *}{n}
$$

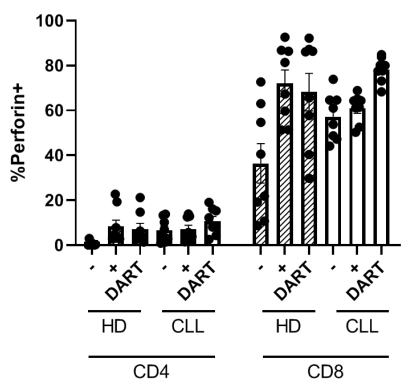

C

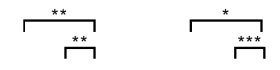

D
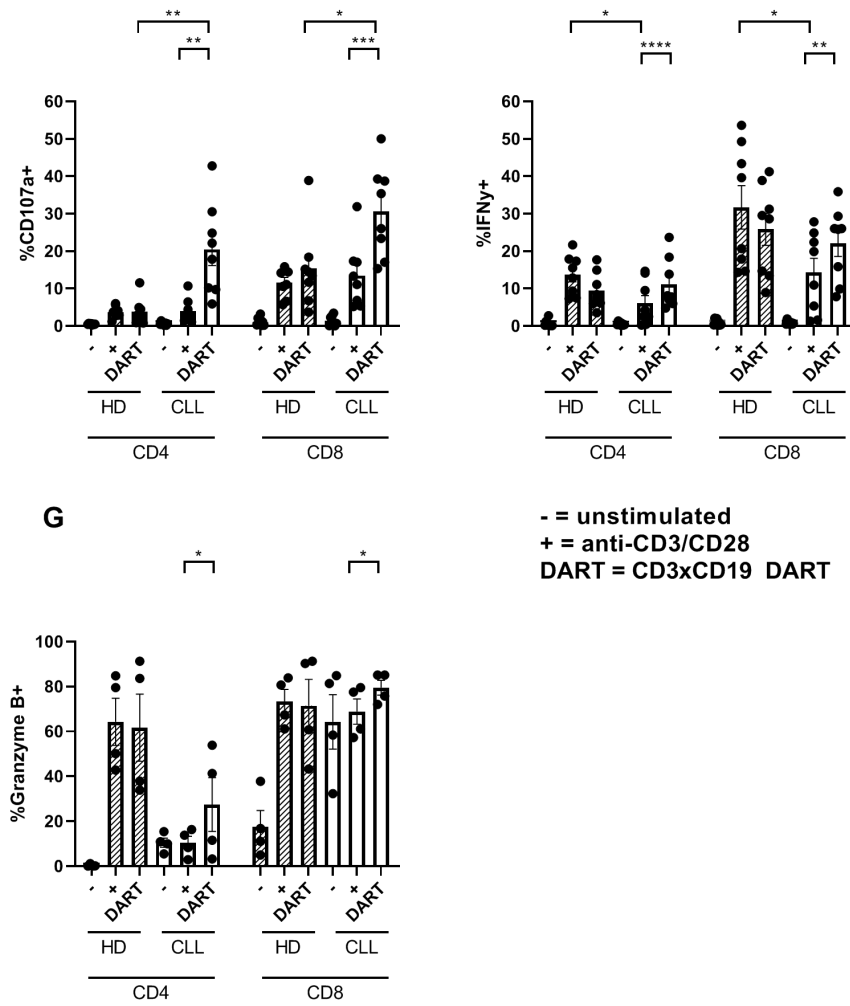

Figure 3 CLL-derived T cells proliferate and activate and produce effector molecules on CD3xCD19 DART in exposure. (A-F) Age-matched HD* or CLL PBMCs were CTV labeled and left unstimulated or in the presence of $100 \mathrm{ng} / \mathrm{mL}$ CD3xCD19 DART or aCD3/aCD28 antibodies. T cell proliferation (A) was measured after 4 days $(n=4)$. (B-G) After 2 days induction of CD25 (B), degranulation measured by CD107a (C), IFNy production (D), TNF $\alpha$ production (E), perforin production (F) and granzyme B production (G) were measured by FACS $(n=4-8)$. *Data from HD PBMCs equal to data in figure $1 A-G$. ${ }^{*} P<0.05 ;{ }^{* *} P<0.01$; ${ }^{\star \star \star} \mathrm{P}<0.001 ;{ }^{* \star \star \star} \mathrm{P}<0.0001$. CLL, chronic lymphocytic leukemia; CTV, cell trace violet; DART, dual affinity re-targeting; HD, healthy donor; IFN $\gamma$, interferon $\gamma$; PBMCs, peripheral blood mononuclear cells; TNF $\alpha$, tumor necrosis factor- $\alpha$.

are also able to lyse CLL cells. Isolated $\mathrm{CD} 4^{+}$or $\mathrm{CD}^{+} \mathrm{T}$ cells from CLL patients were cocultured separately or mixed (CD4:CD8 ratio of 1:1) with JeKo-1, CLL cells from an allogeneic donor, or autologous CLL cells in the presence of $100 \mathrm{ng} / \mathrm{mL}$ CD3xCD19 DART. CLL derived $\mathrm{T}$ cells lysed JeKo- 1 cells very efficiently (figure $4 \mathrm{~A}$ ). CD $4^{+}$ $\mathrm{T}$ cells alone were equally capable of lysing JeKo- 1 or allogeneic CLL cells as CD8 ${ }^{+} \mathrm{T}$ cells, and $\mathrm{CD} 4^{+}$and $\mathrm{CD} 8^{+}$ together. Although slightly lower compared with lysis of JeKo-1 cells, similar results were found for lysis of allogeneic CLL cells (figure 4A). In the autologous setting, the combination of $\mathrm{CD} 4^{+}$and $\mathrm{CD} 8^{+} \mathrm{T}$ cells showed more efficient lysis of autologous CLL cells than either subset alone (figure 4A). The more efficient killing of Jeko-1 compared with primary CLL cells might at least in part be explained by higher expression of CD19 on JeKo-1 compared with primary CLL cells (figure 4B). Coculture of CLL T cells (CD4 and CD8 cells combined, CD4:CD8 ratio as present in donor unknown), with primary CLL and increased dosages of CD3xCD19 DART could not improve killing of primary CLL cells, as a plateau in lysis of CLL cells was already reached at $10 \mathrm{ng} / \mathrm{mL}$ CD3xCD19 DART (figure 4C). In conclusion, CD3xCD19 DART treatment leads to potent lysis of JeKo-1 cells and (autologous) primary CLL cells mediated by patient-derived $\mathrm{T}$ cells.

\section{CLL cells resistant to venetoclax can still be killed upon treatment with CD3xCD19 DART}

The selective Bcl-2 inhibitor venetoclax results in deep responses in blood and bone marrow but seems less effective in eradicating lymph node (LN) residing CLL cells. This might be due to local upregulation of anti-apoptotic molecules such as Bcl-XL and MCL- $1 .{ }^{29}$ We, therefore, assessed effectiveness of CD3xCD19 DART against CLL cells that have acquired an anti-apoptotic profile, after in vitro stimulation by $\mathrm{CD} 40 \mathrm{~L}$, which induces upregulation of Bcl-XL and MCL-1, and leads to venetoclax resistance (online supplementary figure S2A).$^{29}$ On exposure to the CD3xCD19 DART, CD40L-stimulated CLL cells were still effectively lysed by HD T cells (figure 5A). Importantly, CLL cells of a venetoclax-refractory patient could still be lysed on CD3xCD19 DART exposure (online supplementary figure S1I). Furthermore, Bcl-2 overexpressing Ramos cells, which are resistant to apoptotic stimuli such as CD95 or B cell receptor triggering, ${ }^{30}{ }^{31}$ were sensitive to CD3xCD19 DART treatment (figure 5B). These results indicate that a block in intrinsic apoptosis does not prevent $\mathrm{CD}_{1}{ }^{+}$cells from being targeted by CD3xCD19 DART.

CMA inhibited CD3xCD19 DART mediated cell death of CLL cells (figure 5C), implying that killing depends 
A

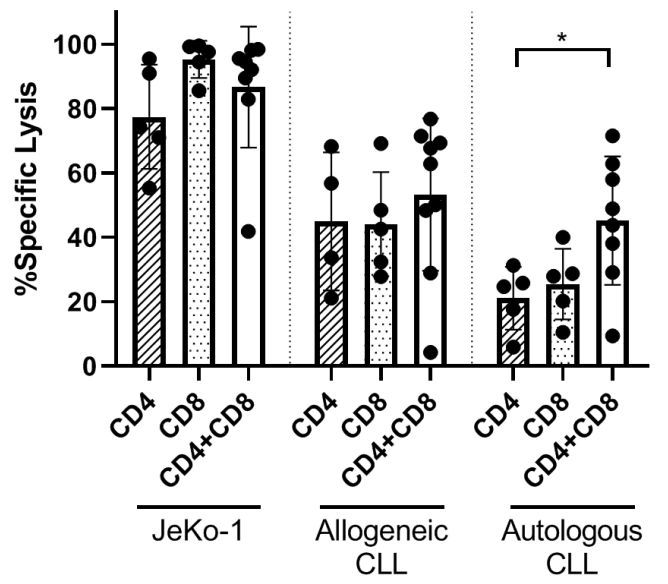

B

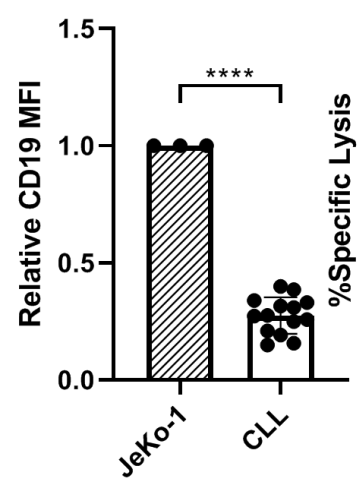

C

Figure 4 CLL-derived T cells kill target cells with CD3xCD19 DART in CLL cocultures. (A) Killing of CTV labeled JeKo-1, allogeneic CLL cells or autologous CLL after 4 days of coculture with $100 \mathrm{ng} / \mathrm{mL}$ CD3xCD19 DART in a 1:1 E:T ratio with CD4 T cells, CD8 T cells or CD4 and CD8 T cells (CD4:CD8 ratio of 1:1) $(n=4-9)(B)$ relative expression of CD19 of JeKo-1 ( $n=3)$ and primary CLL cells $(n=14)$ measured by flow cytometry. (C) killing of CTV labeled CLL after 4 days of coculture with increasing dosages of CD3xCD19 DART in a 1:1 ratio with autologous CLL derived T cells (CD4:CD8 ratio not modified) $(n=3) .{ }^{*} P<0.05$; ${ }^{* \star \star \star P}<<0.0001$.CLL, chronic lymphocytic leukemia; CTV, cell trace violet; DART, dual affinity retargeting; MFI, mean fluorescence intensity.

A

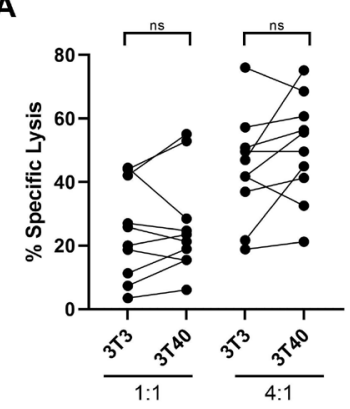

$\mathbf{F}$

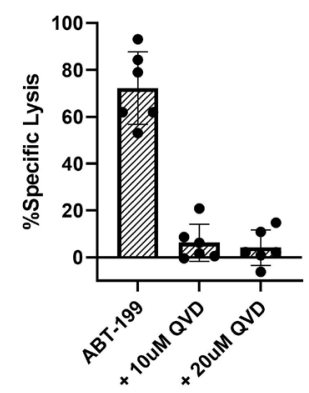

B

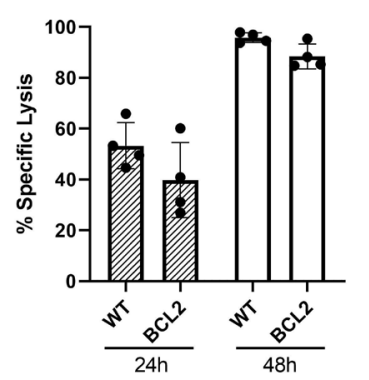

G

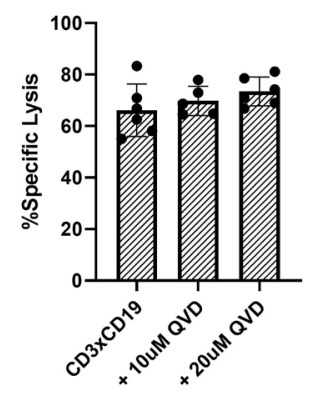

C

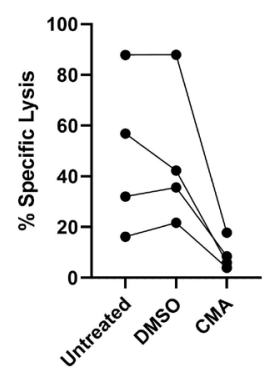

H

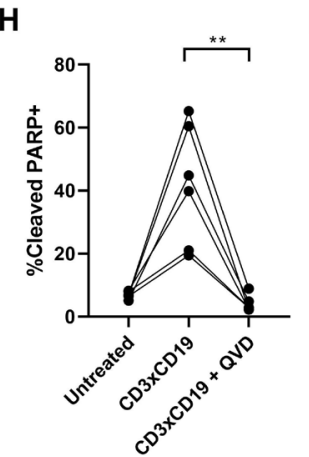

D
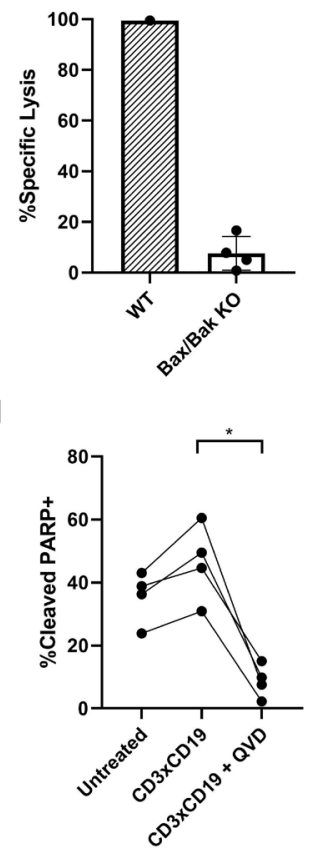

E

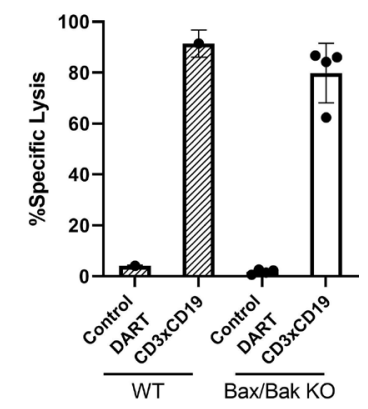

Figure 5 Venetoclax-resistant CLL cells can be killed using CD3xCD19 DART. (A) 3T3 or 3T40 treated CLL cells were cocultured for 24 hours with healthy donor T cells in the presence of $100 \mathrm{ng} / \mathrm{mL}$ CD3xCD19 dart and assessed for viability $(n=10)$. (B) FACS analysis of lysis of WT Ramos or Ramos-Bcl-2 cells on coculture in 4:1 E:T ratio with HD T cells in presence of control or CD3xCD19 DART for 24 and 48 hours $(n=4)$. (C) Specific lysis of coculture of primary CLL cells with untreated, DMSO treated or CMA treated HD T cells in a 4:1 ratio for 2 days $(n=4)$. (D-E) Viability was assessed of mock transfected $(n=1)$ and BAX/BAK KO clones $(n=4)$ after treatment for 24 hours with $(D) 10 \mu \mathrm{M}$ venetoclax or $(E) 100 \mathrm{ng} / \mathrm{mL}$ CD3xCD19 or the control dart molecule in 4:1 E:T ratio with HD T cells. (F-G) Specific lysis of primary CLL (F) treated with 100 nM ABT-199 for 24 hours in presence or absence of QVD-OPh $(n=6)$ or $(G)$ cocultured with HD T cells in 4:1 ratio and $100 \mathrm{ng} / \mathrm{mL}$ CD3xCD19 dart for 4 days in presence or absence of QVD-OPh $(n=6)$. $(\mathrm{H}-\mathrm{l})$ Assessment of cleaved PARP by flow cytometry in $(\mathrm{H})$ JeKo-1 cells cocultured for 24 hours or (I) CLL cells cocultured for 48 hours with HD T cells in a 4:1 ratio in the presence of $100 \mathrm{ng} / \mathrm{mL}$ CD3xCD19 DART, with or without $20 \mu \mathrm{M}$ QVD-OPh $(n=4-6) .{ }^{* *} \mathrm{P}<0.01$. ABT-199, Bcl-2 inhibitor venetoclax; $C L L$, chronic lymphocytic leukemia; CTV, cell trace violet; DART, dual affinity retargeting; HD, healthy donor; ns, not significant; WT, wild type. 
on the perforin and granzyme pathway. ${ }^{32}$ Reported mechanisms of granzyme-mediated lysis of target cells are not conclusive. Initiation of the intrinsic apoptosis pathway through cleavage of Bid, but also direct activation of caspase 3 have been described.$^{33-35}$ To test dependency of CD3xCD19 DART-mediated cell death on the intrinsic apoptosis pathway, BAX/BAK KO JeKo-1 cell-lines were generated (online supplementary figure S2B). Intrinsic apoptosis blockade was confirmed by resistance to venetoclax treatment after 24 hours (figure 5D). Yet, HD T cells caused similar lysis of the $\mathrm{BAX} / \mathrm{BAK} \mathrm{KO}$ and wild type cell-lines (figure $5 \mathrm{E}$ ), implying CD3xCD19 mediated cell death does not depend on the intrinsic apoptosis pathway. We next tested involvement of caspases by using the pan-caspase inhibitor QVD-OPh. QVD-OPh rescued venetoclaxinduced but not CD3xCD19 DART mediated cell death (figure 5F,G). Similar results were obtained using CD40L stimulated CLL or JeKo-1 as target cells (online supplementary figure $\mathrm{S} 2 \mathrm{C}-\mathrm{E}$ ). These data imply that the mechanism of DART molecule mediated T cell-induced cell death is, at least in part, non-apoptotic. This was further confirmed by the induction of PARP cleavage in JeKo-1 and CLL cells after CD3xCD19 DART exposure, which could be fully blocked by addition of QVD$\mathrm{OPh}$ although the cells still died (figure 5H,I). Taken together, CD3xCD19 DART mediated lysis is dependent on granule exocytosis and can potently induce lysis in venetoclax resistant cells, which seems to be independent of BAX/BAK and caspase activity, and therefore seems non-apoptotic.

\section{DISCUSSION}

In this study, we have assessed the effects of a CD3xCD19 targeting DART molecule on CLL in vitro. Our data show that $\mathrm{CD} 19^{+}$cell-lines and primary CLL cells are efficiently lysed by HD T cells using the CD3xCD19 DART. Despite $\mathrm{T}$ cell dysfunction in CLL patients after TCR triggering by anti-CD3/CD28 antibodies, CD3xCD19 DART exposure led to efficient $\mathrm{T}$ cell stimulation, proliferation and production of effector molecules, and efficient lysis of autologous CLL samples by both $\mathrm{CD} 4^{+}$and $\mathrm{CD} 8^{+} \mathrm{T}$ cells. Furthermore, (CD40-stimulated) venetoclax resistant CLL samples were efficiently killed on application of the CD3xCD19 DART. The observed cell death was independent of caspase activity, implying that a non-apoptotic activity is involved in CD3xCD19 DART mediated T cell killing.

When comparing CD3xCD19 DART-induced activation of HD T cells to conventional $\mathrm{T}$ cell stimulation with anti-CD3/CD28 antibodies in vitro, we could not find any differences in terms of activation markers, degranulation, production of effector molecules and proliferation. In contrast, when comparing these conditions in PBMCs from CLL patients, we found superior $\mathrm{T}$ cell function on administration of the CD3xCD19 DART compared with TCR stimulation. CLL T cells have been reported to be deficient in forming immunological synapses on coculture with superantigen pulsed CLL. ${ }^{14}{ }^{15}$ However, using a similar CD3xCD19 bispecific construct, CLL derived $\mathrm{T}$ cells were readily able to form immunological synapses with target cells already after $15 \mathrm{~min}$ of incubation. ${ }^{15} 22$ The immunological synapse might therefore explain improved $\mathrm{T}$ cell function on CD3xCD19 DART treatment, although the exact mechanism remains to be elucidated. $T$ cells receive costimulatory signals at the immunological synapse, which is instrumental for proper T cell activation. ${ }^{36}{ }^{37}$ It has been shown that costimulation via CD28 and 4-1BB enhances the efficacy of T cells modified to express an anti-CD19 BiTE, both in vitro and in vivo. ${ }^{38}$ Since CLL derived T cells are known to be skewed towards a memory/effector phenotype and hence have less $\mathrm{T}$ cells expressing CD28, a role for other costimulatory molecules, such as 4-1BB might be an important explanation as to why CLL derived T cells do not fully respond to anti-CD3/CD28 antibodies, but overcome dysfunctional properties when exposed to CD3xCD19 DART. Nevertheless, costimulation provided by unstimulated CLL cells already seem to be enough to elicit proper $\mathrm{T}$ cell activation in the CD3xCD19 DART setting, since triggering of CLL cells with CD40L, which is known to upregulate costimulatory molecules, does not further enhance lysis of CLL cells. ${ }^{39}$

Classically, $\mathrm{CD}^{+} \mathrm{T}$ cells are viewed as the main cytotoxic $\mathrm{T}$ cell, but in recent years it has become more clear that $\mathrm{CD}^{+} \mathrm{T}$ cells also have the capability to differentiate into cytotoxic lymphocytes. Cytotoxic $\mathrm{CD}^{+}{ }^{+} \mathrm{T}$ cells were mainly observed in chronic viral infections and inflammation, but they have recently also been implied to play a role in antitumor responses. ${ }^{40-43}$ Here, we demonstrate that $\mathrm{CD} 4^{+} \mathrm{T}$ cells are also able to induce target lysis on CD3xCD19 DART exposure. Surprisingly, we observed that CLL derived $\mathrm{CD} 4^{+} \mathrm{T}$ cells produced less granzyme B compared with their HD derived counterpart on stimulation with $\mathrm{CD} 3 \times \mathrm{CD} 19$ DART or anti-CD3/CD28 stimulation. It has been observed that granzyme $\mathrm{B}$ positive $\mathrm{CD} 4^{+}$produce $\mathrm{IFN} \gamma$ and have a Th1 phenotype. ${ }^{44}$ Whether CLL derived $\mathrm{CD}^{+} \mathrm{T}$ cells are indeed more skewed toward a Th2 phenotype remains to be elucidated, since conflicting results have been reported so far. ${ }^{45-47}$ Nevertheless, $\mathrm{CD}^{+} \mathrm{T}$ cells performed as well as $\mathrm{CD}^{+}$or a combination of $\mathrm{CD}^{+}$and $\mathrm{CD} 8^{+} \mathrm{T}$ cells in inducing lysis of JeKo-1 or allogeneic CLL samples. The fact that the CLL derived T cells were not HLA-matched might have contributed to the increased cytotoxic $\mathrm{CD}^{+} \mathrm{T}$ cell response that was observed. In an autologous setting, where HLA-mismatching is irrelevant, $\mathrm{CD} 4^{+} \mathrm{T}$ cells were equally potent in killing autologous CLL as CD8 ${ }^{+}$ $\mathrm{T}$ cells. Interestingly, in this setting presence of both $\mathrm{CD}^{+}$and $\mathrm{CD}^{+}$in a 1:1 ratio significantly increased target cell lysis. Since it is mostly the $\mathrm{CD}^{+} \mathrm{T}$ cells that produce cytotoxic molecules like perforin and granzyme $\mathrm{B}$, it shows that potent $\mathrm{CD} 8^{+}$mediated autologous antitumor responses can be further enhanced by the 
presence of $\mathrm{CD}^{+} \mathrm{T}$ cells, which can potentiate cytokine production. ${ }^{48}$ Nevertheless, it remains to be elucidated what would be the ideal $\mathrm{T}$ cell composition for optimal CD3xCD19 DART mediated responses. CAR $\mathrm{T}$ cell research has shown that 1:1 CD4:CD8 ratios in the CAR T cell product may be beneficial for clinical responses, ${ }^{4950}$ although this does not seem to be the case for all CAR T cell products. ${ }^{51}$ Since CLL patients are reported to have a reduced CD4:CD8 ratio, this might be worthwhile to investigate. ${ }^{52} 53$

Cell death induced by both venetoclax and chemotherapy has been characterized as apoptosis. However, anti-apoptotic profiles in CLL are induced both in the LNs as well as on treatment with chemotherapy, due to upregulation of the anti-apoptotic molecules MCL-1 and BCL-XL or Bfl-1, respectively. ${ }^{29}{ }^{54}$ Although venetoclax is effective, LN residing CLL cells are less sensitive to this drug, and mechanisms of resistance to this relatively new therapy have already been described. ${ }^{3}$ Our data indicate that after in vitro CD40L stimulation, a model mimicking the LN, venetoclax resistant CLL can still be targeted using CD3xCD19 DART. This indicates that CD3xCD19 DART mediated cell death is regulated differently compared with venetoclax or chemotherapy induced lysis, and therefore could be a valuable addition to the CLL therapy arsenal.

The observed CD3xCD19 DART mediated killing by $\mathrm{T}$ cells was granule dependent and therefore likely dependent on granzyme B. The present data demonstrate that CD3xCD19 DART mediated lysis is not dependent on $\mathrm{BAX} / \mathrm{BAK}$ and therefore the intrinsic apoptotic pathway is not necessary to induce cell death, as shown previously for purified granzyme B and cytotoxic $\mathrm{T}$ cell mediated killing. ${ }^{556}$ Furthermore, cell death still occurred when caspases, and subsequent PARP cleavage, were blocked by using QVD-OPh, further indicating that CD3xCD19 DART mediated killing is non-apoptotic. Previously, similar T cell mediated cell death has been observed in an in vitro setting using mouse cytotoxic lymphocytes, in which caspase inhibition did not rescue cell death of peptide pulsed mouse embryonic fibroblasts. ${ }^{57}$

Where apoptosis is usually defined as a form of immunologically silent cell death, other forms like necrosis and necroptosis are generally proinflammatory. ${ }^{58}$ In immunotherapy settings, it therefore might be beneficial to induce a proinflammatory type of cell death to boost the immune system. Indeed, inducing intratumoral necroptosis of fibroblasts in a melanoma mouse model increased tumor-antigen loading on antigen presenting cells as well as durable tumor clearance in combination with ICB, indicating that inducing proinflammatory cell death leads to enhanced tumor clearance ${ }^{59}$ However, it remains to be elucidated how cell death is characterized in CD3xCD19 DART-mediated setting on caspase inactivation, and whether this form of cell death is also relevant in an in vivo setting.

\section{CONCLUSIONS}

Our data indicate that CD3xCD19 DART therapy might be a feasible option for autologous based $\mathrm{T}$ cell therapy in CLL. CD3xCD19 DART exposure results in robust T cell stimulation and even venetoclax resistant samples are still sensitive to CD3xCD19 DART mediated lysis. Therefore, CD3xCD19 DART treatment might have potential in CLL in combination with targeted therapies or as salvation therapy after venetoclax relapse.

\section{Author affiliations}

${ }^{1}$ Department of Experimental Immunology, Amsterdam Infection \& Immunity Institute, Amsterdam UMC, Amsterdam, The Netherlands

${ }^{2}$ Department of Hematology, Cancer Center Amsterdam and Lymphoma and Myeloma Center Amsterdam, Amsterdam UMC, Amsterdam, The Netherlands ${ }^{3}$ Janssen Pharmaceutical Companies of Johnson and Johnson, Philadelphia, Pennsylvania, USA

${ }^{4}$ Department of Internal Medicine, Zuyderland Medical Centre Heerlen, Heerlen, The Netherlands

Correction notice Figure $5 \mathrm{I}$ has been updated. 1 patient was removed from the figure since the patient which was originally labeled as chronic lymphocytic leukemia, has been recently rediagnosed as indolent CD5+ mantle cell lymphoma.

Acknowledgements The authors thank the patients and healthy donors for their blood donations.

Contributors AWJM, SRJ, HA, LI, SHT, EE, GJWvdW and AK designed research; AWJM, SRJ and IAMD performed research; AWJM and SRJ analyzed data; RvK provided patient samples and reviewed the paper; and AWJM, EE, GJWvdW and AK wrote the paper.

Funding This work was supported by the Netherlands Organisation for Scientific Research (NWO)/Netherlands Organisation for Health Research and Development (ZonMw) VIDI grant and Janssen Pharmaceuticals Companies of Johnson and Johnson.

Competing interests $\mathrm{AK}$ and $\mathrm{EE}$ have sponsored research grants from Janssen Pharmaceutical Companies of Johnson \& Johnson. HA and LI are employees of Janssen Pharmaceutical Companies of Johnson \& Johnson. GJWvdW is employee of Genmab.

\section{Patient consent for publication Not required.}

Ethics approval The study was approved by the medical ethics committee at Amsterdam UMC (ethics approval number 2013/159).

Provenance and peer review Not commissioned; externally peer reviewed.

Data availability statement Data are available on reasonable request. All data relevant to the study are included in the article or uploaded as online supplementary information. The datasets used and/or analysed during the current study are available from the corresponding author on reasonable request.

Open access This is an open access article distributed in accordance with the Creative Commons Attribution Non Commercial (CC BY-NC 4.0) license, which permits others to distribute, remix, adapt, build upon this work non-commercially, and license their derivative works on different terms, provided the original work is properly cited, appropriate credit is given, any changes made indicated, and the use is non-commercial. See http://creativecommons.org/licenses/by-nc/4.0/.

ORCID iD

Anne W J Martens http://orcid.org/0000-0003-0858-2482

\section{REFERENCES}

1 Kipps TJ, Stevenson FK, CJ W, et al. Chronic lymphocytic leukaemia. Nat Rev Dis Primers 2017;3:17008.

2 Ahn IE, Underbayev C, Albitar A, et al. Clonal evolution leading to ibrutinib resistance in chronic lymphocytic leukemia. Blood 2017;129:1469-79.

3 Blombery P, Anderson MA, Gong J-nan, et al. Acquisition of the recurrent Gly101Val mutation in $\mathrm{Bcl} 2$ confers resistance to 
venetoclax in patients with progressive chronic lymphocytic leukemia. Cancer Discov 2019;9:342-53.

4 Dreger P, Döhner H, Ritgen M, et al. Allogeneic stem cell transplantation provides durable disease control in poor-risk chronic lymphocytic leukemia: long-term clinical and MRD results of the German CLL Study Group CLL3X trial. Blood 2010;116:2438-47.

5 Dreger P, Schetelig J, Andersen N, et al. Managing high-risk CLL during transition to a new treatment era: stem cell transplantation or novel agents? Blood 2014;124:3841-9.

6 van Gelder M, de Wreede LC, Bornhäuser M, et al. Long-Term survival of patients with CLL after allogeneic transplantation: a report from the European Society for blood and marrow transplantation. Bone Marrow Transplant 2017;52:372-80.

7 Gribben JG, Zahrieh D, Stephans K, et al. Autologous and allogeneic stem cell transplantations for poor-risk chronic lymphocytic leukemia. Blood 2005;106:4389-96.

8 Park JH, Rivière I, Gonen M, et al. Long-Term follow-up of CD19 CAR therapy in acute lymphoblastic leukemia. $N$ Engl $J$ Med 2018;378:449-59.

9 Hopfinger G, Jäger U, Worel N. Car-T cell therapy in diffuse large B cell lymphoma. HemaSphere 2019;3:e185.

10 Xu-Monette ZY, Zhou J, Young KH. Pd-1 expression and clinical PD-1 blockade in B-cell lymphomas. Blood 2018;131:68-83.

11 Ding W, LaPlant BR, Call TG, et al. Pembrolizumab in patients with CLL and Richter transformation or with relapsed CLL. Blood 2017;129:3419-27.

12 Brentjens RJ, Rivière I, Park JH, et al. Safety and persistence of adoptively transferred autologous CD19-targeted T cells in patients with relapsed or chemotherapy refractory B-cell leukemias. Blood 2011;118:4817-28.

13 Porter DL, Hwang W-T, Frey NV, et al. Chimeric antigen receptor T cells persist and induce sustained remissions in relapsed refractory chronic lymphocytic leukemia. Sci Trans/ Med 2015;7:303-139.

14 Riches JC, Davies JK, McClanahan F, et al. T cells from CLL patients exhibit features of T-cell exhaustion but retain capacity for cytokine production. Blood 2013;121:1612-21.

15 Ramsay AG, Johnson AJ, Lee AM, et al. Chronic lymphocytic leukemia $T$ cells show impaired immunological synapse formation that can be reversed with an immunomodulating drug. $J$ Clin Invest 2008;118:2427-37.

16 Mackus WJM, Frakking FNJ, Grummels A, et al. Expansion of CMVspecific CD8+CD45RA+CD27- T cells in B-cell chronic lymphocytic leukemia. Blood 2003;102:1057-63.

17 te Raa GD, Pascutti MF, García-Vallejo JJ, et al. Cmv-Specific CD8+ T-cell function is not impaired in chronic lymphocytic leukemia. Blood 2014:123:717-24.

18 van Bruggen JAC, Martens AWJ, Fraietta JA, et al. Chronic lymphocytic leukemia cells impair mitochondrial fitness in CD8+ T cells and impede CAR T-cell efficacy. Blood 2019;134:44-58.

19 Topp MS, Gökbuget N, Stein AS, et al. Safety and activity of blinatumomab for adult patients with relapsed or refractory Bprecursor acute lymphoblastic leukaemia: a multicentre, single-arm, phase 2 study. Lancet Oncol 2015;16:57-66.

20 Topp MS, Gökbuget N, Zugmaier G, et al. Long-Term followup of hematologic relapse-free survival in a phase 2 study of blinatumomab in patients with MRD in B-lineage all. Blood 2012;120:5185-7.

21 Wong R, Pepper C, Brennan P, et al. Blinatumomab induces autologous T-cell killing of chronic lymphocytic leukemia cells. Haematologica 2013;98:1930-8.

22 Robinson HR, Qi J, Cook EM, et al. A CD19/CD3 bispecific antibody for effective immunotherapy of chronic lymphocytic leukemia in the ibrutinib era. Blood 2018;132:521-32.

23 Nagorsen D, Kufer P, Baeuerle PA, et al. Blinatumomab: a historical perspective. Pharmacol Ther 2012;136:334-42.

24 Liu L, Lam C-YK, Long V, et al. MGD011, a CD19 X CD3 Dual-Affinity retargeting bi-specific molecule incorporating extended circulating half-life for the treatment of B-cell malignancies. Clin Cancer Res 2017;23:1506-18.

25 Circosta P, Elia AR, Landra I, et al. Tailoring CD19xCD3-DART exposure enhances T-cells to eradication of B-cell neoplasms. Oncoimmunology 2018;7:e1341032.

26 Hallaert DYH, Jaspers A, van Noesel CJ, et al. C-Abl kinase inhibitors overcome CD40-mediated drug resistance in CLL: implications for therapeutic targeting of chemoresistant niches. Blood 2008;112:5141-9.

27 O'Neill KL, Huang K, Zhang J, et al. Inactivation of prosurvival $\mathrm{Bcl}-2$ proteins activates Bax/Bak through the outer mitochondrial membrane. Genes Dev 2016;30:973-88.
28 Amin HM, McDonnell TJ, Medeiros LJ, et al. Characterization of 4 mantle cell lymphoma cell lines. Arch Pathol Lab Med 2003;127:424-31.

29 Thijssen R, Slinger E, Weller K, et al. Resistance to ABT-199 induced by microenvironmental signals in chronic lymphocytic leukemia can be counteracted by CD20 antibodies or kinase inhibitors. Haematologica 2015;100:e302-6.

30 van der Kolk LE, Evers LM, Omene C, et al. CD20-induced B cell death can bypass mitochondria and caspase activation. Leukemia 2002;16:1735-44.

31 Eldering E, Mackus WJM, Derks IAM, et al. Apoptosis via the $B$ cell antigen receptor requires Bax translocation and involves mitochondrial depolarization, cytochrome $c$ release, and caspase- 9 activation. Eur J Immunol 2004;34:1950-60.

32 Kataoka T, Shinohara N, Takayama H, et al. Concanamycin A, a powerful tool for characterization and estimation of contribution of perforin- and Fas-based lytic pathways in cell-mediated cytotoxicity. $J$ Immunol 1996;156:3678-86.

33 Barry M, Heibein JA, Pinkoski MJ, et al. Granzyme B shortcircuits the need for caspase 8 activity during granule-mediated cytotoxic T-lymphocyte killing by directly cleaving Bid. Mol Cell Biol 2000;20:3781-94.

34 Metkar SS, Wang B, Ebbs ML, et al. Granzyme B activates procaspase-3 which signals a mitochondrial amplification loop for maximal apoptosis. J Cell Biol 2003;160:875-85.

35 Yang X, Stennicke HR, Wang B, et al. Granzyme B mimics apical caspases. description of a unified pathway for trans-activation of executioner caspase-3 and -7. J Biol Chem 1998;273:34278-83.

36 Dustin ML, Shaw AS. Costimulation: building an immunological synapse. Science 1999;283:649-50.

37 Chen L, Flies DB. Molecular mechanisms of T cell co-stimulation and co-inhibition. Nat Rev Immunol 2013;13:227-42.

38 Velasquez MP, Szoor A, Vaidya A, et al. Cd28 and 41BB costimulation enhances the effector function of CD19-specific Engager T cells. Cancer Immunol Res 2017;5:860-70.

39 Kater AP, Evers LM, Remmerswaal EBM, et al. Cd40 stimulation of Bcell chronic lymphocytic leukaemia cells enhances the anti-apoptotic profile, but also Bid expression and cells remain susceptible to autologous cytotoxic T-lymphocyte attack. Br J Haematol 2004;127:404-15.

40 Juno JA, van Bockel D, Kent SJ, et al. Cytotoxic CD4 T Cells-Friend or foe during viral infection? Front Immunol 2017;8:19.

41 Thewissen M, Somers V, Hellings N, et al. CD4 ${ }^{+}$CD28 ${ }^{\text {null }}$ T Cells in Autoimmune Disease: Pathogenic Features and Decreased Susceptibility to Immunoregulation. J Immunol 2007;179:6514-23.

42 Matsuzaki J, Tsuji T, Luescher IF, et al. Direct tumor recognition by a human CD4+ T-cell subset potently mediates tumor growth inhibition and orchestrates anti-tumor immune responses. Sci Rep 2015;5:14896.

43 Quezada SA, Simpson TR, Peggs KS, et al. Tumor-reactive CD4+ T cells develop cytotoxic activity and eradicate large established melanoma after transfer into lymphopenic hosts. J Exp Med 2010;207:637-50.

44 van Leeuwen EMM, Remmerswaal EBM, Vossen MTM, et al. Emergence of a CD4 ${ }^{+} \mathrm{CD}_{28}{ }^{-}$Granzyme B ${ }^{+}$, CytomegalovirusSpecific T Cell Subset after Recovery of Primary Cytomegalovirus Infection. J Immunol 2004:173:1834-41.

45 Podhorecka M, Dmoszynska A, Rolinski J, et al. T type 1/type 2 subsets balance in B-cell chronic lymphocytic leukemia - the threecolor flow cytometry analysis. Leuk Res 2002;26:657-60.

46 Palma M, Gentilcore G, Heimersson K, et al. T cells in chronic lymphocytic leukemia display dysregulated expression of immune checkpoints and activation markers. Haematologica 2017;102:562-72.

47 Görgün G, Holderried TAW, Zahrieh D, et al. Chronic lymphocytic leukemia cells induce changes in gene expression of CD4 and CD8 T cells. J. Clin. Invest. 2005;115:1797-805.

48 Laidlaw BJ, Craft JE, Kaech SM. The multifaceted role of CD4+ T cells in CD8+ T cell memory. Nat Rev Immunol 2016;16:102-11.

49 Turtle CJ, Hanafi L-A, Berger C, et al. CD19 CAR-T cells of defined CD4+:CD8+ composition in adult B cell ALL patients. J Clin Invest 2016;126:2123-38.

50 Turtle CJ, Hanafi L-A, Berger C, et al. Immunotherapy of nonHodgkin's lymphoma with a defined ratio of CD8 ${ }^{+}$and CD4 ${ }^{+} \mathrm{CD} 19-$ specific chimeric antigen receptor-modified T cells. Sci Trans/ Med 2016;8:355-116.

51 Fraietta JA, Lacey SF, Orlando EJ, et al. Determinants of response and resistance to CD19 chimeric antigen receptor (CAR) T cell therapy of chronic lymphocytic leukemia. Nat Med 2018;24:563-71.

52 Christopoulos P, Pfeifer D, Bartholomé K, et al. Definition and characterization of the systemic T-cell dysregulation in 
untreated indolent B-cell lymphoma and very early CLL. Blood 2011;117:3836-46.

53 Kimby E, Mellstedt $\mathrm{H}$, Nilsson B, et al. T lymphocyte subpopulations in chronic lymphocytic leukemia of B cell type in relation to immunoglobulin isotype(s) on the leukemic clone and to clinical features. Eur J Haematol 1987;38:261-7.

54 Morales AA, Olsson A, Celsing F, et al. High expression of bfl-1 contributes to the apoptosis resistant phenotype in B-cell chronic lymphocytic leukemia. Int J Cancer 2005;113:730-7.

55 Goping IS, Sawchuk T, Rieger A, et al. Cytotoxic T lymphocytes overcome Bcl-2 inhibition: target cells contribute to their own demise. Blood 2008;111:2142-51.
56 Thomas DA, Scorrano L, Putcha GV, et al. Granzyme B can cause mitochondrial depolarization and cell death in the absence of Bid, Bax, and Bak. Proc Natl Acad Sci U S A 2001;98:14985-90.

57 Pardo J, Wallich R, Martin P, et al. Granzyme B-induced cell death exerted by ex vivo CTL: discriminating requirements for cell death and some of its signs. Cell Death Differ 2008;15:567-79.

58 Green DR, Ferguson T, Zitvogel L, et al. Immunogenic and tolerogenic cell death. Nat Rev Immunol 2009;9:353-63.

59 Snyder AG, Hubbard NW, Messmer MN, et al. Intratumora activation of the necroptotic pathway components RIPK1 and RIPK3 potentiates antitumor immunity. Sci Immunol 2019;4:eaaw2004. 